\title{
Towards the integration of culture into \\ the Unified Theory of Acceptance and Use of Technology
}

\section{Nicolae Nistor, Thomas Lerche, Armin Weinberger, Ciprian Ceobanu and Jan Oliver Heymann}

Nicolae Nistor is a Research Fellow at the Faculty of Psychology and Educational Sciences, Ludwig-Maximilians-Universität München, Germany; Contributing Faculty at Richard W. Riley College of Education and Leadership, Walden University, USA; and, at the moment, visiting scholar at the Department of Learning Science, Hiroshima University, Japan. Thomas Lerche is an Assistant Professor at the Faculty of Psychology and Educational Sciences, Ludwig-Maximilians-Universität München, Germany. Armin Weinberger is a Professor of Educational Technology and Knowledge Management at Saarland University, Germany. Ciprian Ceobanu is an Associate Professor at the Teachers Training Department of the Faculty of Psychology and Educational Sciences at the "Alexandru Ioan Cuza" University of Iași, Romania. Jan Oliver Heymann is a graduate student of Educational Sciences at Ludwig-Maximilians-Universität München, Germany. Address for correspondence: Dr. Nic. Nistor, Ludwig-Maximilians-Universität, Faculty of Psychology and Educational Sciences, Leopoldstr. 13, D-80802 München, Germany. Email: nic.nistor@uni-muenchen.de 


\section{Practitioner notes}

What is already known about this topic

- Technology acceptance models (TAMs) include technology use behaviour, use intention, individual believes about technology use, and several context variables as moderators.

- A prominent TAM is the Unified Theory of Acceptance and Use of Technology (UTAUT), which is however insufficiently validated in culturally diverse settings.

- Geert Hofstede describes culture using several dimensions that include masculinity, individualism and uncertainty avoidance.

- Scarce and isolated research results suggest moderating influences of Hofstede's cultural dimensions in educational TAMs; an overall picture is missing.

What this paper adds

- Based on a culturally diverse sample of nearly 3000 participants, UTAUT is validated with respect to computers as learning tools, while suggesting the integration of three cultural dimensions in UTAUT.

- The results confirm a positive influence of cultural masculinity on performance expectancy, and a negative influence on effort expectancy.

- Cultural individualism may reduce the perceived social influence with respect to the adoption of educational technologies.

- Uncertainty avoidance may increase computer anxiety, amplify the influence of effort expectancy on the use intention and the influence of computer anxiety on the use behaviour, and impede technology use.

Implications for practice and/or policy

- In intercultural and cross-cultural settings, learners' acceptance of educational technology may depend on their cultural background.

- National culture is likely to have the strongest influence on acceptance mechanisms; nevertheless, professional culture plays also a significant role.

- Depending on culture, performance and effort expectancy, social influence and computer anxiety may be different, and have different influences on educational technology acceptance.

- Culture may serve as a customizing criterion for the design of technology-based educational settings. 


\title{
Towards the integration of culture into \\ the Unified Theory of Acceptance and Use of Technology
}

\begin{abstract}
Educational technology is increasingly used in multicultural contexts and across national cultures. Educational technology users with different national and professional backgrounds may, however, exhibit different attitudes towards technology. Previous research provides isolated evidence of the relationship between learning technology acceptance and culture, and so an overall picture is missing. Therefore, this study attempts to integrate culture (sensu Hofstede, 2001) into an established technology acceptance model (ie. the Unified Theory of Acceptance and Use of Technology, UTAUT, Venkatesh, Morris, Davis \& Davis, 2003). Examining a large sample $(\mathrm{N}=2866)$ of learning technology users from Germany and Romania by means of questionnaire survey, we investigate the differences in culture and technology acceptance between sample subgroups. The collected data reveal the presence of cultural differences both between countries and between professions. In line with previous research, these differences are associated with dissimilar acceptance profiles, ie. different values of acceptance variables and of path coefficients between them. Based on the findings, this study makes headway in cross-cultural research by proposing an extended model of UTAUT - one which integrates three of Hofstede's culture dimensions. As a practical implication, national and professional culture may shape computer-based learning environments.
\end{abstract}

\section{Introduction}

Several scholarly efforts have been made during the last few decades to understand the factors contributing to educational technology acceptance (ETA), most notable being the technology acceptance models (eg. Davis, 1989; Venkatesh et al., 2003; Venkatesh, Thong \& $\mathrm{Xu}, 2012$ ). In such studies, little attention has been paid to culture. Most of the available ETA studies were conducted in the USA, and only occasionally in other countries (eg. Venkatesh \& Zhang, 2010; Teo, Luan \& Sing, 2008). Also, since new technologies seem to be introduced first in technological or administrative domains, many ETA studies involve participants with professions in the fields of science, technology, engineering or mathematics (eg. Venkatesh et al., 2003; 2012). This prevents forming a general image about the national and professional culture influence on ETA. Therefore, acceptance theories and models need additional validation from cultural perspective. 
Against this background, the present paper provides a validation of the Unified Theory of Acceptance and Use of Technology (UTAUT; Venkatesh et al., 2003; 2012), putting in prime focus the moderating influence of cultural values induced by users' nation and profession. In the context of the European Union, where studies of ETA, with or without taking culture into consideration, are still scarce, we examine these aspects comparatively in Germany, a founding member of the EU, and in Romania, a new EU member. The validation is based on a sample that is larger than in previous studies, and displays higher diversity in terms of participants' culture and profession. We finally attempt to draw an overall picture that integrates culture dimensions into the UTAUT.

\section{Literature review}

\section{Educational technology acceptance}

Technology acceptance models are based on the view of acceptance as an attitude towards technology. In the context of technology adoption, the reasoned action and planned behavior approach (Ajzen \& Fishbein, 2000) resulted in several theories, of which the most frequently studied in educational settings is the Technology Acceptance Model (TAM; Davis, 1989), with his various versions. Venkatesh and his colleagues (2003; also Venkatesh, Thong \& Xu, 2012) formulate their Unified Theory of Acceptance and Use of Technology (UTAUT) as a synthesis of previous TAM versions, and describe technology use under the influence of use intention, further determined by performance expectancy, effort expectancy, and social influence. Additionally, facilitating conditions directly determine technology usage. The influence of the predictors named above on behavioral intention and use behavior is moderated by users' age, sex, experience, and by the voluntariness of use. In a recent study, Nistor, Wagner, Istvánffy and Dragotă (2010) report findings that are consistent with Venkatesh et al. $(2003,2012)$, but increase the explanatory power of the UTAUT model by additionally considering the role of computer anxiety for ETA (cf. Beaudry \& Pinsonneault, 2010). However, these findings are based on samples of up to several hundreds of participants (eg. $\mathrm{N}=215$ in Venkatesh et al., 2003; $\mathrm{N}=1512$ in Venkatesh et al., 2012) displaying little diversity. The majority of the participants appear to be young technology users from Western countries, mostly with technological and administrative professions. 
Some recent studies mentioned below involve cultural diversity and open thus a research line worth pursuing.

\section{Culture}

There are numerous definitions of culture, in general (Triandis, 1972), as well as of technological culture (Leidner \& Kayworth, 2006). Hofstede (2001) defines culture as patterns of thinking, feeling and potential acting, which have been learned throughout a lifetime, and which are likely to be used repeatedly and unlikely (or difficult) to be changed by the individual. Cultural patterns are shared within a social environment such as nation, ethnicity or profession. In available cross-cultural ETA research literature (eg. Cronjé, 2011; Keller, Lindh, Hrastinki, Casanovas \& Fernandez, 2009; Leidner \& Kayworth, 2006; Li, Chau \& Van Slyke, 2010; Nistor et al., 2010; Teo, Luan \& Sing, 2008; Veltri \& Elgarah, 2009; Venkatesh \& Zhang, 2010; Zakour, 2007), different cultures are compared using samples from different countries, thus tacitly equating culture with national culture, ie. geographical location. This is a rough approximation, since timely stable patterns of thinking, feeling and potential acting may strongly vary within national borders. However, for the purpose of this research, we speak of national cultures defined by nationality or geographic location. Additionally, we examine professional cultures, defined by individual education and professional practice in a given domain.

Hofstede (2001; Hofstede \& McCrae, 2004) describes culture using five dimensions:

- PDI: Power distance index represents the extent to which the less powerful members of a culture accept the unequal distribution of power within the same culture.

- UAI: Uncertainty avoidance deals with the intolerance for unstructured, ie. novel, unknown, surprising or unusual situations that the members of a society show.

- IDV: Individualism (vs. collectivism) refers to the quality of ties between individuals, and to the degree of integration into cohesive groups within society.

- MAS: Masculinity (vs. femininity) refers to the distribution of emotional roles between the sexes. In masculine cultures, the gap between the values of men and women is wider than in feminine cultures; thus, men are more assertive and competitive, while women are more modest and caring than in feminine cultures. 
- LTO: Long-term orientation (vs. short-term orientation) comprises values such as thrift and perseverance, as opposed to respect for tradition, the fulfillment of social obligations and face-saving, which are representative of short-term orientation.

Table 1 gives an overview of the available cultural scores for Germany (Hofstede, 2012) and Romania (Luca, 2005). Hofstede and McCrae (2004) argue that these dimensions of culture are linked to individual personality traits, thus connecting the individual with the social level. They report significant correspondence between the cultural dimensions and general personality models, eg. between individualism and extroversion, or between uncertainty avoidance, neuroticism, and agreeableness. On this ground, Venkatesh and Zhang (2010) assimilate gender to cultural masculinity in their discussion of cultural influences on ETA. Similarly, we assimilate in this paper individually perceived risk to uncertainty avoidance (see below).

Table 1: Hofstede's (2012) cultural dimensions for Germany and Romania

\begin{tabular}{lccccc}
\hline Country & PDI & IDV & MAS & UAI & LTO \\
\hline Germany (Hofstede, 2012) & 35 & 67 & 66 & 65 & 31 \\
\hline Romania (Gallup study; Luca, 2005) & $29 / 33^{*}$ & 49 & 39 & 61 & 42 \\
\hline
\end{tabular}

* Luca (2005) presents two Gallup studies, which slightly differ with respect to the PDI scores.

\section{The influence of culture on educational technology acceptance}

A few recent studies apply Hofstede's view of culture values within the frame of UTAUT, assuming that attitudes towards educational technology co-vary with cultural dimensions.

- Relying on the UTAUT variables, Venkatesh and Zhang (2010) expect the effect of performance expectancy on the behavioral intention to be amplified, and the effect of effort expectancy to be diminished by cultural or individual masculinity. Also, Im, Kim and Han (2008) hypothesize the effect of both expectancies to be diminished by the perceived risk (which in our opinion may be assimilated to uncertainty avoidance).

- Zakour (2007) expects individualism to act as a moderator of the social influence on ETA, ie. in individualistic cultures the social influence on ETA should be weaker (cf. Venkatesh and Zhang, 2010).

- By definition, we may expect computer anxiety to be stronger per se and have a stronger effect on ETA in uncertainty avoidant cultures. Uncertainty avoidance has also been 
regarded as an anxiety-reducing strategy, as Beaudry and Pinsonneault (2010) suggest. In this view, technology may not necessarily induce anxiety in members of uncertainty avoidant cultures.

- Finally, technology use intention should be directly influenced by uncertainty avoidance (Veltri \& Elgarah, 2009) or, respectively, by perceived risks (Im et al., 2008), so that technology users would show less use intention in uncertainty avoidant cultures.

However, these are isolated research results; an overall picture of the relationship of ETA and culture, which would integrate cultural dimensions and UTAUT, is still missing.

\section{Research questions}

To make a first step towards the integration of culture into UTAUT, we examine both the direct influence of culture on UTAUT variables, and its moderating influence within the model (cf. Leidner \& Kayworth, 2006).

The influence of national culture. To what extent do Romanian and German users of educational technology differ with respect to (a) cultural values sensu Hofstede, (b) attitudes towards educational technology, and (c) the corresponding relationships between acceptance variables as described by UTAUT?

The influence of professional culture. To what extent do participants with professions in STEM (ie. science, technology, engineering and mathematics) vs. non-STEM fields differ with respect to (a) cultural values sensu Hofstede, (b) attitudes towards educational technology, and (c) the corresponding relationships between acceptance variables as described by UTAUT?

\section{Methodology}

A correlation study was conducted, recording data in a one-shot survey from various educational technology users. For this purpose, we chose people with an academic degree, including faculty and teachers, from universities, schools and adult education centres, and university students. The sample $(\mathrm{N}=2866)$ was chosen randomly within a range aimed at 
overcoming the limits of the previous studies, and provided diversity in terms of national culture ( $n=1017$ participants from Romania, $n=1849$ from Germany), professional culture ( $n=867$ participants had professions in STEM fields, ie. science, technology, engineering, and mathematics; $n=1998$ in non-STEM fields).

The independent variables performance expectancy, effort expectancy, social influence, facilitating conditions and computer anxiety were measured, as well as the dependent variables use intention and use behavior. Additionally, the demographic variables age, sex, geographic location and profession were recorded. The research instrument consisted of German and a Romanian translations of the questionnaire proposed by Venkatesh et al. (2003) with variable values ranging from $1=$ very low to $5=$ very high acceptance. Aimed at surveying general attitudes and intentions towards technology, the questions were framed about "the computer as a learning tool", with specific references to office software, information search on the Internet, communication and interactions between Internet users (eg. e-mail, discussion forums, chat etc), and e-learning. The participants' cultural values were measured using the Values Survey Model VSM94 (Hofstede, 2012).

Data was collected between February 2008 and January 2010, calling for voluntary participation, partially online $(n=2123)$ and partially using pen-and-paper forms $(n=743)$. Data analysis was performed using IBM SPSS Statistics version 19 and R version 2.11.1 (using Lavaan version 0.4-9 and SEM version 0.9-21).

\section{Results}

\section{Generic results}

To re-validate the questionnaire proposed by Venkatesh and colleagues $(2003,2012)$ in the new cultural setting, a confirmatory factor analysis was performed, demonstrating convergent and discriminant validity of the instrument. The comparative fit index (CFI) of the confirmatory factor analysis was .93 , describing thus an adequate model fit. The mean values of the UTAUT variables for the Romanian and German participants, as well as for the entire sample are displayed in tab. 2. A two-tailed $t$ test showed significant differences in all acceptance variables between the two subgroups. The extended UTAUT model (ie. containing the computer anxiety as additional variable, cf. Nistor et al., 2010) was tested for 
the entire sample. Due to the complexity of the verified model, the method of structural equations modeling with latent variables was chosen. The resulting path coefficients are shown in fig. 1 . The model's goodness of fit CFI $=.933$ is adequate, and the chi-square test is significant, $p<.05$ (Hu \& Bentler, 1999). However, since RMSEA < .06 and SRMR < .05 slightly exceed the level of acceptable fit, some restrictions have to be considered in the result interpretation. As for cultural differences, MANOVA results show that the influence of national culture on Hofstede's cultural dimensions and attitudes towards educational technology is large, $F(4,2822)=118.42, p<.001, \eta^{2}=.25$, whereas profession influence is small, $F(4,5644)=6.26, p<.001, \eta^{2}=.02$, and interaction effects can be disregarded, $F(4,2822)=1.92$, n.s.

Table 2: Values of the UTAUT variables for the entire sample and for the cultural subgroups

\begin{tabular}{lccccc}
\hline & $\begin{array}{c}\text { Entire sample } \\
(\mathrm{N}=2866)\end{array}$ & $\begin{array}{c}\text { Romanians } \\
(\mathrm{n}=1017)\end{array}$ & $\begin{array}{c}\text { Germans } \\
(\mathrm{n}=1849)\end{array}$ & $\begin{array}{c}\text { STEM } \\
\text { professions } \\
(n=867)\end{array}$ & $\begin{array}{c}\text { Non-STEM } \\
\text { professions } \\
(n=1998)\end{array}$ \\
\hline $\begin{array}{l}\text { Performance } \\
\text { expectancy }\end{array}$ & $\mathrm{M}(\mathrm{SD})$ & $\mathrm{M}(\mathrm{SD})$ & $\mathrm{M}(\mathrm{SD})$ & $\mathrm{M}(\mathrm{SD})$ & $\mathrm{M}(\mathrm{SD})$ \\
$\begin{array}{l}\text { Effort } \\
\text { expectancy }\end{array}$ & $1.99(.78)$ & $1.80(.62)$ & $2.10(.84)$ & $1.86(.73)$ & $2.05(.80)$ \\
$\begin{array}{l}\text { Social } \\
\text { influence }\end{array}$ & $3.47(.89)$ & $3.92(.71)$ & $3.23(.89)$ & $3.63(.87)$ & $3.40(.89)$ \\
$\begin{array}{l}\text { Facilitating } \\
\text { conditions }\end{array}$ & $3.84(.70)$ & $3.78(.61)$ & $3.88(.74)$ & $3.95(.67)$ & $3.80(.70)$ \\
$\begin{array}{l}\text { Computer } \\
\text { anxiety }\end{array}$ & $1.94(.93)$ & $2.21(.96)$ & $1.80(.88)$ & $1.83(.91)$ & $2.00(.93)$ \\
$\begin{array}{l}\text { Use intention } \\
\text { Use behavior }\end{array}$ & $3.77(1.13)$ & $4.09(.90)$ & $3.60(1.21)$ & $3.90(1.08)$ & $3.71(1.14)$ \\
\hline
\end{tabular}

Table 3: Hofstede's cultural scores for the cultural subgroups

\begin{tabular}{lcccc}
\hline & $\begin{array}{c}\text { Romanians } \\
(n=1017)\end{array}$ & $\begin{array}{c}\text { Germans } \\
(n=1849)\end{array}$ & $\begin{array}{c}\text { STEM } \\
\text { professions } \\
(n=867)\end{array}$ & $\begin{array}{c}\text { Non-STEM } \\
\text { professions } \\
(n=1998)\end{array}$ \\
\hline $\begin{array}{l}\text { Power distance index } \\
\text { (PDI) }\end{array}$ & 20.1 & 36.1 & 27.3 & 32.1 \\
$\begin{array}{l}\text { Collectivism vs. } \\
\text { individualism (IDV) }\end{array}$ & 67.4 & 92.5 & 78.2 & 85.9 \\
$\begin{array}{l}\text { Masculinity vs. } \\
\text { femininity (MAS) }\end{array}$ & 38.5 & -29.9 & 12.7 & -13.3 \\
$\begin{array}{l}\text { Uncertainty avoidance } \\
\text { (UAI) }\end{array}$ & 65.2 & 76.9 & 67.0 & 75.2 \\
$\begin{array}{l}\text { Long-term orientation } \\
\text { (LTO) }\end{array}$ & 53.7 & 45.6 & 50.1 & 47.8 \\
\hline
\end{tabular}




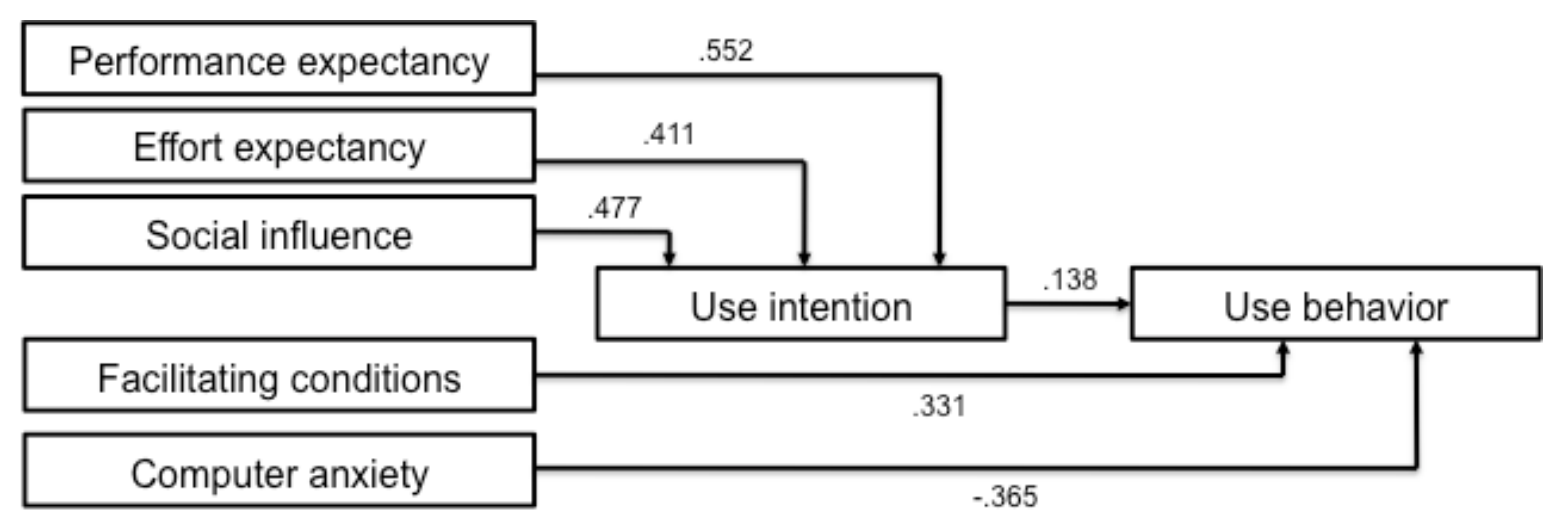

Figure 1: Verification of the extended UTAUT model with path coefficients for the entire sample

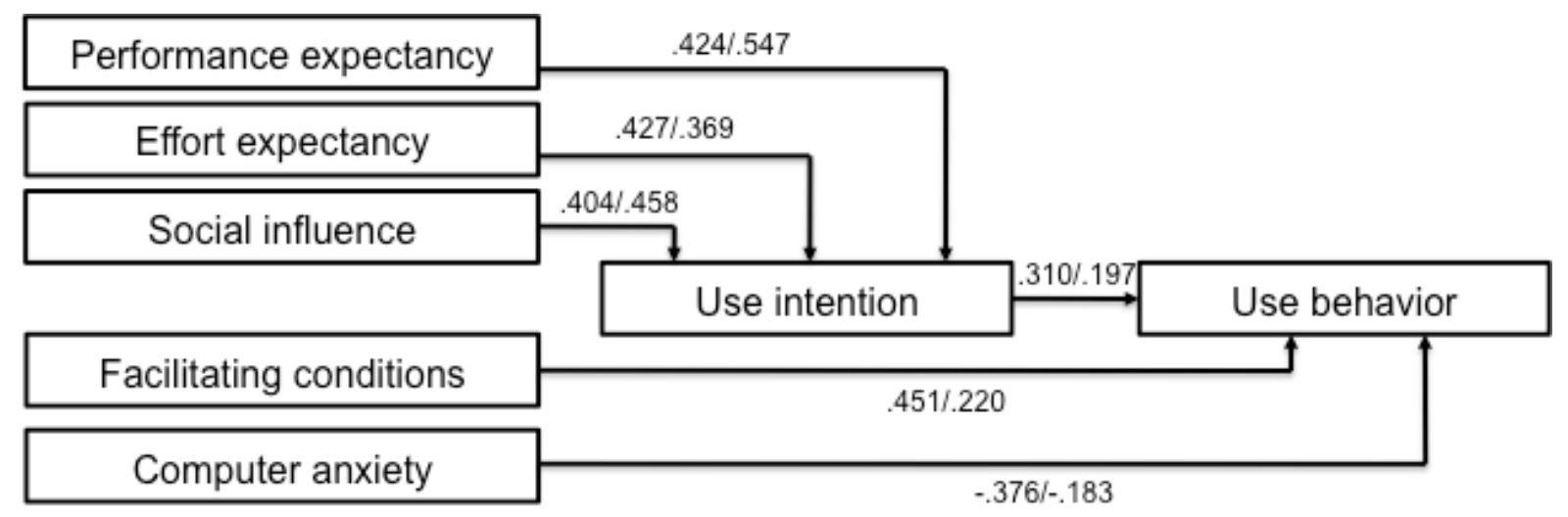

Figure 2: The extended UTAUT model with path coefficients for Romanian/German educational technology users

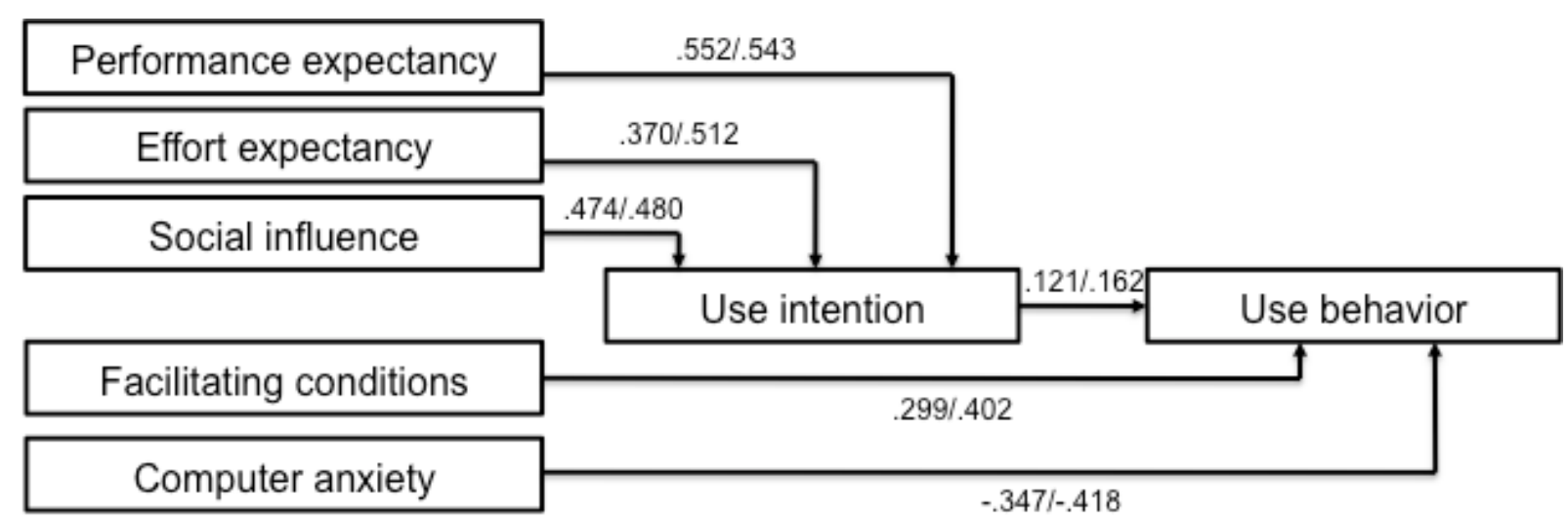

Figure 3: The extended UTAUT model with path coefficients for participants with STEM vs. non-STEM professions 
Regarding participants' attitudes towards educational technology, Romanians have a significantly more positive attitude, higher anxiety and a stronger intention to use educational technology than Germans (tab. 2). Further, Hofstede's cultural dimension scores show that Romanian users are less power distant, more collectivistic, more masculine, less uncertainty avoidant and more long-time oriented than the German users (tab. 3). Further details concerning participants' acceptance were extracted by repeating the structural equations procedure described above and testing the extended UTAUT model separately for Romanians and Germans. As shown in fig. 2, Romanians' use behavior is stronger influenced by the facilitating conditions, participants' computer anxiety and by the use intention than that of Germans. Romanian participants' use intention is less influenced by performance expectancy, more by effort expectancy, and is slightly less subjected to social influence.

\section{The influence of professional culture}

Observing the differences between professional groups related to Hofstede's cultural dimensions, the participants with STEM professions were less power distant, exhibited lower values on collectivism, were more masculine, less uncertainty avoidant, and more long-time oriented than the participants with non-STEM professions (tab. 2). As for participants' attitudes towards educational technology, those with STEM professions showed higher performance expectancy, lower effort expectancy, perceived more social influence and better facilitating conditions, and had lower computer anxiety, higher use intention and use behavior (tab. 3). All differences are statistically significant, but their effect size is small. With respect to the path coefficients of the extended UTAUT model (fig. 3), the use behavior of the learners having a STEM profession is somewhat weaker influenced by use intention, facilitating conditions and computer anxiety. As for the predictors of the use intention, there is a significant difference in the influence of the effort expectancy, which is stronger for nonSTEM professionals. 


\section{Summary of findings and discussion}

This paper has examined the influence of ethnic and professional cultures on ETA. Based on a large sample representing two different European nations (ie. German and Romanian) and different professions (ie. STEM and non-STEM), our study has offered evidence for different cultural profiles corresponding to nation and profession. In comparing the Romanian vs. German and the non-STEM vs. STEM sub-samples, national culture displays the strongest influence on ETA, however both affecting learners' attitudes towards learning technology and moderating the effect of these attitudes on the use intention and use behavior.

The influence of national culture. From the national-cultural perspective, Romanian learning technology users appear to be less authoritarian, less individualistic, more masculine, less uncertainty avoidant, and more long-term oriented. Comparing these results with previously reported figures from Romania (Luca, 2004), our findings are quite similar with respect to MAS and UAI. The differences in PDI, IDV and LTO may be interpreted as an evolution of the Romanian culture in the past decades, perhaps reorienting itself from the Eastern European, communist culture to the Western European, democratic one, and thus becoming less power-distant and more individualistic. Long-term orientation may have increased in Romania in the late 1990s due to society resettling after the transition from communism to democracy. The noticeable negative value of the masculinity index for Germans (MAS $=-29.9$ ) is certainly different from the findings reported by previous research, and generally infrequent among Hofstede's cultural dimensions; however, it appears to be possible and acceptable (Hofstede, 2012).

Attitudes towards educational technology build different acceptance profiles for Romanians and Germans. Compared to Germans, Romanians display higher performance expectancy, lower effort expectancy, higher social influence, lower perceived facilitating conditions, higher computer anxiety, higher use intention, and lower technology use. Although performance expectancy is higher for Romanians, it has a weaker influence on the use intention. Conversely, effort expectancy is lower and its influence on the use intention is somewhat stronger. National culture moderates the influence of effort expectancy on use intention, and the influence of facilitating conditions on use behavior. On this ground, we could verify the following hypotheses: 
- The hypothesis that (individual or cultural) masculinity would emphasize the performance expectancy and let effort expectancy play a secondary role is supported by our data, but only with reference to the values of the two UTAUT variables and not for their effects as formulated by Im et al. (2008) and Venkatesh and Zhang (2010).

- Further, since Germans seem to be more uncertainty avoidant, and their influence of effort expectancy on behavioral intention is weaker than that of Romanians', the hypothesis by Im et al. (2008) is supported by our data. This support is however only partial, since this effect is inversed with respect to performance expectancy.

- A similar pattern was found with respect to individualism and social influence. According to our data, Germans are more individualistic than Romanians. Also, their social influence scores are much lower that those of Romanians. The effect of social influence on use intention is however slightly stronger for Germans than for Romanians. Thus, Zakour's (2007) hypothesis is supported only with respect to the values of the UTAUT variables, not the regression coefficients.

- Romanians are less uncertainty avoidant than the Germans; at the same time, they display higher computer anxiety and a stronger effect of computer anxiety on use behavior. This result is counterintuitive and it suggests the existence of factors with a stronger influence than culture and attitudes, eg. long-term exposure of large, ethnic or professional groups to insufficient or inappropriate infrastructure, resulting in negative experiences with technology (Sarker \& Valacich, 2010).

- Finally, Germans are more uncertainty avoidant and they show less intention to use learning technology; thus, the hypothesis formulated by Veltri and Elgarah (2009) is supported by our data.

The influence of professional culture. Our results support the hypothesized existence of an IT culture (Leidner \& Kayworth, 2006) that is subordinated to the national culture and has an influence on ETA. The technology users with non-STEM professions appear to be more authoritarian, more individualistic, more feminine, more uncertainty avoidant, and less longterm oriented. A negative value for masculinity can be observed here, as well. Caution is necessary when interpreting all these differences, since no significance test is available for Hofstede's dimensions. The influence of the professional culture on ETA is weaker, yet significant. Compared to STEM professionals, non-STEM professionals display lower performance expectancy, higher effort expectancy, lower social influence, lower perceived facilitating conditions, higher computer anxiety, lower use intention, and lower technology 
use. Non-STEM professionals perceive their computer literacy higher than STEM professionals. As for the moderating influence of profession on the UTAUT model, there are small, yet significant differences in the influences of effort expectancy on use intention, and of use intention, facilitating conditions and computer anxiety on the use behavior. Altogether, we could corroborate the hypotheses gathered from the research literature.

- Since the STEM culture displays higher scores for masculinity and performance expectancy, lower scores for effort expectancy, and, at the same time, a weaker effect of performance expectancy and a stronger effect of effort expectancy on the use intention, the hypotheses formulated by Im et al. (2008) and Venkatesh and Zhang (2010) are supported only with reference to the values of the two UTAUT variables, not to their effects on the use intention.

- Further, since non-STEM professionals seem to be more uncertainty avoidant, and their influence of effort expectancy on behavioral intention is weaker than those of STEM professionals, this part of the hypothesis by Im et al. (2008) is supported by our data. The effect is inversed with respect to performance expectancy, and thus contrary to the first part of the hypothesis.

- A similar pattern was found with respect to individualism and social influence. According to our data, non-STEM professionals are more individualistic than STEM professionals. Their social influence scores are lower that those of the STEM professionals. The social influence on use intention is, however, slightly stronger for non-STEM professionals than for STEM professionals. Thus, Zakour's (2007) hypothesis is supported only with respect to the values of the UTAUT variables, not to the regression coefficients.

- STEM professionals are less uncertainty avoidant than non-STEM professionals, while at the same time displaying lower computer anxiety and a weaker effect of computer anxiety on use behavior. This hypothesis is thus supported.

- Finally, STEM professionals make more use of learning technology and are less uncertainty avoidant, thereby supporting the hypothesis formulated by Veltri and Elgarah (2009).

Besides the confirmation of cultural differences between ethnic (Romanian vs. German) and professional (STEM vs. non-STEM) subgroups, we used these differences as a setting for a quasi-experimental approach, in which differences in the cultural context are associated with 
differences in ETA. Our results are consistent with previous research, and suggest the following interdependences:

- Masculinity may have a positive influence on performance expectancy and a negative influence on effort expectancy (cf. Im et al., 2008; Venkatesh \& Zhang, 2010).

- Individualism may reduce the perceived social influence with respect to the adoption of learning technologies (cf. Zakour, 2007).

- Uncertainty avoidance may have a positive influence on computer anxiety and amplify the influence of effort expectancy on the use intention and the influence of computer anxiety on the use behavior. At the same time, it may have a direct negative influence on the use of technology (cf. Veltri \& Elgarah, 2009).

Since these interdependences have not yet been the validated like the other influences synthesized by the UTAUT, and proven by statistical procedures, they are represented in fig. 4 as dashed lines added to the extended UTAUT model.

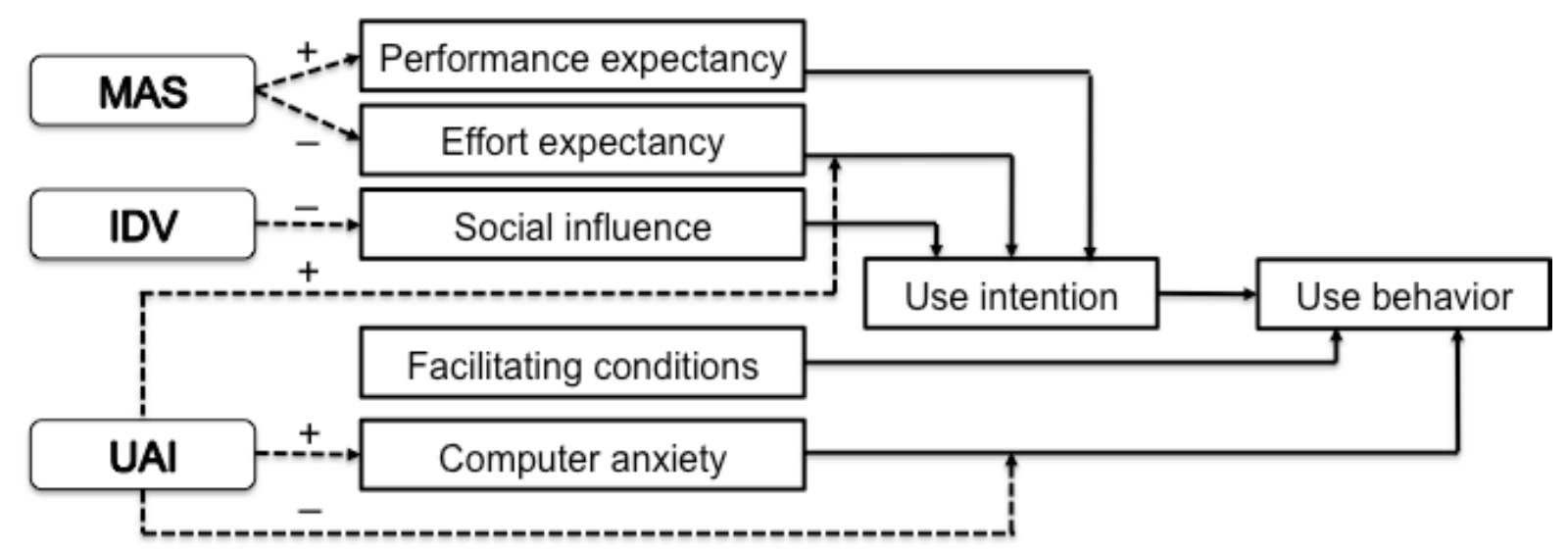

Figure 4: Integrating Hofstede's cultural dimensions into the extended UTAUT model ( $M A S=$ masculinity, $I D V=$ individualism, $U A I=$ uncertainty avoidance $)$

This study placed an emphasis on theory and aimed at additional validation of the UTAUT model, attempting to integrate Hofstede's (2001) cultural dimensions into the extended UTAUT (Venkatesh et al., 2003; 2012; Nistor et al., 2010). Thus, it enlarges the picture of the relationship of ETA and culture, still restricted in recent research. For educational practice, this study suggests that acceptance and Hofstede's culture dimensions are appropriate starting points when dealing with cultural discrepancies in the context of 
technology-enhanced learning. Different learners may have different expectations with respect to the design and outcome of computer-enhanced learning environments, and need different support, eg. in order to successfully deal with computer anxiety. Relying on the paradigm of mass-customization (Nistor, Dehne \& Drews, 2010), technology-enhanced learning environments may therefore be designed for specific groups of users defined by national and professional culture.

The aim of a large sample including an appropriate diversity of participants was reached. On the other hand, the corresponding methodology led to several limitations of the study. The collected data was entirely based on self-report, which may inflate the correlations between variables (Podsakoff, MacKenzie, Lee \& Podsakoff, 2003). The media mix used for the survey made it difficult to ascertain the response vs. non-response rate. The paper and pencil method was used more in Romania, and favoured the participation of less computerexperienced persons; these may also have been more anxious and thus more dependent of adequate facilitating conditions. For the extended UTAUT model, the RMSEA and SRMR indexes exceed the level of acceptable fit, nevertheless the model's goodness of fit CFI = .933 was adequate ( $\mathrm{Hu} \&$ Bentler, 1999), therefore this limitation may be regarded as acceptable, as well. Future research should provide instruments that overcome these limitations. Also, research should examine the interaction of cultural and economical factors influencing the educational technology infrastructure and its acceptance. 


\section{Acknowledgements}

The authors would like to thank Astrid Arauner, Laura Bărgăoanu, Tina Busche, Virgil Dan, Maria Dragotă, Emese Istvánffy, Lorena Mureșan and Maximilian Wagner for contributing to data collection; to Frank Fischer, Karsten Stegmann and Freydis Vogel for valuable suggestions to the statistical data processing; to Florian Schultz-Pernice and Ilse-Maria Vandory for English language editing.

\section{References}

Ajzen, I. \& Fishbein, M. (2000). Attitudes and the attitude-behaviour relation: Reasoned and automatic processes. European Review of Social Psychology, 11, 1-33.

Beaudry, A. \& Pinsonneault, A. (2010). The other side of acceptance: Studying the direct and indirect effects of emotions on information technology use. MIS Quarterly, 34 (4), 689710.

Cronjé, J. C. (2011). Using Hofstede's cultural dimensions to interpret cross-cultural blended teaching and learning. Computers \& Education, 56, 596-603.

Davis, F. (1989). Perceived usefulness, perceived ease of use, and user acceptance of information technology. MIS Quarterly, 13, 319-340.

Hofstede, G. (2001). Culture's consequences: Comparing values, behaviors, institutions and organizations across nations. Thousand Oaks, CA: Sage.

Hofstede, G. (2012). VSM 94. Retrieved online 04/13/2012 at: http://www.geerthofstede.nl /vsm-94

Hofstede, G. \& McCrae, R. R. (2004). Personality and culture revisited: Linking traits and dimensions of culture. Cross-Cultural Research, 38 (1), 52-88.

Hu, L. \& Bentler, P.M. (1999). Cutoff criteria for fit indexes in covariance structure analysis: Conventional criteria versus new alternatives. Structural Equation Modeling, 6 (1), 1-55.

Im, I., Kim, Y. \& Han, H. J. (2008). The effects of perceived risk and technology type on users' acceptance of technologies. Information \& Management, 45, 1-9.

Keller, C., Lindh, J., Hrastinski, S., Casanovas, I. \& Fernandez, G. (2009). The impact of national culture on e-learning implementation: a comparative study of an Argentinean and a Swedish university. Educational Media International, 46 (1), 67-80.

Leidner, D. E. \& Kayworth, T. (2006). A review of culture in information systems research: Toward a theory of information technology culture conflict. MIS Quarterly, 30 (2), 357399.

Li, D., Chau, P. Y. K. \& Van Slyke, C. (2010). A comparative study of individual acceptance of instant messaging in the US and China: A structural equation modeling approach. Communications of the Association for Information Systems, 26 (5), 85-106.

Luca, A. (2005). Studiu despre valorile și comportamentul românesc din perspectiva dimensiunilor culturale după metoda lui Geert Hofstede [A study of Romanian values and behavior from the perspective of Geert Hofstede's cultural dimensions]. Bucharest: Interact. Retrieved online 04/13/2012 at: http://www.training.ro/ docs/studiu2.pdf

Nistor, N., Dehne, A. \& Drews, F. T. (2010). Mass customization of teaching and training in organizations. Design principles and prototype evaluation. Studies in Continuing Education, 32 (3), 251-267. 
Nistor, N., Wagner, M., Istvánffy, E. \& Dragotă, M. (2010). The Unified Theory of Acceptance and Use of Technology: Verifying the model from a European perspective. International Journal of Knowledge and Learning, 6 (2-3), 185-199.

Podsakoff, P. M., MacKenzie, S. B., Lee, J. Y. \& Podsakoff, N. P. (2003). Common method bias in behavioral research: A critical review of the literature and recommended remedies. Journal of Applied Psychology, 88 (5), 879-903.

Pynoo, B., Tondeur, J., Brak, J., Duyck, W., Sijnave, B. \& Duyck, P. (2012). Teachers' acceptance and use of an educational portal. Computers \& Education, 58, 1308-1307.

Sarker, S. \& Valacich, J. S. (2010). An alternative to methodological individualism: A nonreductionist approach to studying technology adoption by groups. MIS Quarterly, 34 (4), 779-808.

Teo, T., Luan, W. S., \& Sing, C. C. (2008). A cross-cultural examination of the intention to use technology between Singaporean and Malaysian pre-service teachers: an application of the Technology Acceptance Model (TAM). Educational Technology \& Society, 11 (4), 265-280.

Triandis, , H. C. (1972). The analysis of subjective culture. New York: John Wiley.

Veltri, N. \& Elgarah, W. (2009). The role of national culture in social networking adoption. In C. F. Rogers \& Y. C. Chen (Eds.), Proceedings of the 12th Annual Conference of the Southern Association for Information Systems (pp. 169-174). Statesboro, GA: Georgia Southern University. Retrieved online 04/13/2012 at: http://ut.academia.edu/NatashaVeltri/ Papers/1269313/The_role_of_national_cultural_differences_in_user_adoption_of_social_n etworking

Venkatesh, V., Morris, M. G., Davis, G. B. \& Davis, F. D. (2003). User acceptance of information technology: Toward a unified view. MIS Quarterly, 27, 425-478.

Venkatesh, V., Thong, J. Y. L. \& Xu, X. (2012). Consumer acceptance and use of information technology: Extending the Unified Theory of Acceptance and Use of Technology. MIS Quarterly, 36 (1), 157-178.

Venkatesh, V. \& Zhang, X. (2010). The Unified Theory of Acceptance and Use of Technology: U.S. vs. China. Journal of Global Information Technology Management, 13 (1), 5-27.

Zakour, A. B. (2007). Information technology acceptance across cultures. In W. K. Law (Ed.), Information resources management: global challenges (pp. 25-53). Hershey, PA: Idea. 